\title{
ANALISIS KESEDIAAN MEMBAYAR PENGUNJUNG TERHADAP PAKET WISATA PENDIDIKAN LINGKUNGAN DI TAMAN WISATA ALAM WIRA GARDEN KOTA BANDAR LAMPUNG
}

\author{
Willingness to Pay Analysis of Visitors for the Environmental Education Travel Packageat \\ Wira Garden Nature Tourism Park in Bandar Lampung
}

\author{
Puspita Octaria ${ }^{\mathrm{a}}$,Sri Mulatsih ${ }^{\mathrm{b}}$, Meti Ekayani ${ }^{\mathrm{c}}$ \\ a Program Studi Pengelolaan Sumberdaya Alamdan Lingkungan Sekolah Pasca Sarjana, Institut Pertanian Bogor, \\ Kampus IPB Dramaga, Bogor, 16680 -octaria.puspita@yahoo.com \\ ${ }^{b}$ Departemen Agribisnis, Fakultas Ilmu Ekonomi, Institut Pertanian Bogor, Kampus IPB Dramaga, Bogor, 16680 \\ ${ }^{c}$ Departemen Ekonomi Sumber daya dan Lingkungan, Fakultas Ekonomi Manajemen, Institut Pertanian Bogor, \\ Kampus IPB Dramaga, Bogor, 16680
}

\begin{abstract}
Lampung is province in Indonesia which is trying to generate income through tourism sectors. One of them is Wira Garden Nature Park (TWA). Wira Garden is located in Bandar Lampung. Activities from tourist increasly effects increase garbage that impact on aesthetics and environmental quality in Wira Garden. So that, takes antourism program based on environmental education. That is able to educate visitors so visitors will participated in activities that aim to promote concern in environment, especially nature tourism. Focus of planning an tourism program based on environmental education is creating environmental education packages, by two activities are planting trees and deposit garbage (deposit refund). Manager of Wira Garden collaborate with BSCH (Bank Sampah Cangkir Hijau) to build garbage deposit program (deposit refund). Environmental education programs in Wira Garden is realized into three types options that are (Personal Green), (Garden Family) and (Jungle Community). Funding for this program is expected from income of (WTP) Willingness to Pay from visitors in Wira Garden.
\end{abstract}

Keywords: deposit refund, education travel package, waste management, (WTP) Willingness To Pay

(Diterima: 24-11-2016; Disetujui: 28-03-2017)

\section{Pendahuluan}

Jumlah wisatawan yang berkunjung ke kawasan wisata di sekitar Provinsi Lampung mulai meningkat dalam jangka waktu tiga tahun terakhir (2010-2013), yaitu sebesar 1.177.551 wisatawan. Data ini berdasarkan jumlah kunjungan wisatawan lokal maupun asing yang menginap di hotel dan akomodasi lainnya di Provinsi Lampung (BPS Provinsi Lampung, 2014). Sementara itu data rekapitulasi terakhir sampai dengan bulan November 2014 jumlah wisatawan asing yang datang ke Provinsi Lampung mencapai 69 ribu orang (Disbudpar Provinsi Lampung, 2014). Taman Wisata Alam (TWA) Wira Garden merupakan salah satu TWA yang berada di Kota Bandar Lampung. TWA yang sudah berdiri selama lima tahun ini mempunyai harapan kedepannya untuk meningkatkan jumlah wisatawan. Harapan peningkatan pengunjung atau wisatawan, tentunya diupayakan secara beriringan melalui perbaikan kualitas lingkungan lewat penawaran program paket wisata berbasis pendidikan. Sektor pariwisata pada umumnya mampu mendatangkan keuntungan ekonomi, namun di sisi lain berpotensi menimbulkan kerusakan lingkungan dan penurunan nilai estetika lingkungan. Merujuk pada Sunu (2010) bahwa perkembangan industri (jasa) yang diikuti dengan pembangunan fisik yang semakin meningkat tanpa didukung oleh usaha kelestarian lingkungan akan mempercepat proses kerusakan alam.Kawasan wisata alam merupakan tempat yang bersentuhan langsung dengan alam, sehingga dibutuhkan suatu konsep pengelolaan yang bersifat berkelanjutandemi keberlangsungan lingkungan TWA. Menurut Sudiarta (2006), membantu pelestarian atau konservasi alam merupakan bagian dari ekowisata. Kebiasaan membuang sampah sembarangan oleh pengunjung, hal ini tidak cukup teratasi dengan hanya memberlakukan aturan maupun himbauan, namun membutuhkan tindakan nyata untuk dapat merubah kebiasaan tersebut.

Merujuk pada pendapat Sumarwoto (2001) setiap aktivitas baik secara pribadi maupun kelompok, pasti menghasilkan sisa yang tidak berguna dan kemudian menjadi barang buangan (sampah), atau dengan kata lain sampah merupakan konsekuensi dari adanya aktivitas manusia, dan setiap manusia pasti menghasilkan buangan atau sampah. Demikian juga halnya dengan pengunjung di TWA Wira Garden yang terbiasa membuang sampah sembarangan. Oleh karena itu pengelola TWA Wira Garden mencoba membangun suatu konsep wisata alam berbasis pendidikan lingkungan, agar kegiatan berwisata dapat melibatkan partisipasi pengunjung sehingga lebih 
perduli terhadap kebersihan, kelestarian lingkungan dan sebagai sarana untuk menjembatani beberapa masalah yang ditimbulkan dari kunjungan wisatawan di TWA Wira Garden. Hal ini sejalan dengan pendapat yang dikemukakan Sander (2010), bahwa interaksi antara pengunjung dan objek wisata telah dapat menyampaikan pesan pendidikan sehingga wisatawan mengalami perubahan sikap dan pandangannya terhadap lingkungan kearah positif. Gagasan program berbasis pendidikan lingkungan yang ingin pengelola berlakukan terfokus pada dua jenis kegiatan. Kegiatan tersebut diantaranya penanaman bibit pohon, dan kegiatan deposit sampah (deposit refund). Pemberlakuan dua kegiatan tersebut akan dikemas dalam tiga jenis alternatif pilihan paket wisata pendidikan lingkungan (personal green, garden family, dan jungle community). Khusus untuk kegiatan (deposit refund), pengelola bekerjasama dengan BSCH (Bank Sampah Cangkir Hijau) sebagai fasilitator untuk mengakomodir kegiatan penukaran sampah pengunjung dan rcycling untuk pengadaan souvenir wisata. Adapun untuk memberlakukan program paket wisata pendidikan lingkungan dibutuhkan sejumlah biaya. Biaya tersebut diharapkan bisa dipenuhi dari penerimaan tiket masuk. Oleh karena itu perlu diestimasi penerimaan berdasarkan tarif tiket saat ini dan WTP pengunjung. Selain itu perlu juga dikaji biaya operasional paket wisata pendidikan lingkungan berdasarkan WTP, dan biaya covering dari pemberlakuan paket wisata pendidikan lingkungan, di TWA Wira Garden.

WTP digunakan karna dapat menganalisis preferensi individu mengenai produk non-use, serta mampu mengidentifikasi barang dan jasa yang akan dievaluasi atau pasar hipotetik yang diacu. Skenarioskenario yang akan ditawarkan kepada pengunjung berupa paket wisata berbasis pendidikan lingkungan yang diharapkan dapat menimbulkan partisipasi pengunjung untuk lebih menjaga kelestarian lingkungan dalam upaya pengendalian sampah dan konservasi lingkungan.

Menurut Pearce et al. (1994), kesediaan untuk membayar atau WTP (Willingness to Pay) adalah kesediaan individu untuk membayar terhadap suatu kondisi lingkungan atau penilaian terhadap sumberdaya alam dan jasa alami dalam rangka memperbaiki kualitas lingkungan.

\section{Metode Penelitian}

\subsection{Waktu dan Lokasi Penelitian}

Penelitian ini dilakukan di Taman Wisata Alam Wira Garden yang lokasinya terletak pada Kelurahan Batu Putu Kecamatan Tajungkarang Barat Kota Bandar Lampung. Waktu penelitian dilaksanakan mulai bulan Juni hingga Agustus 2014.
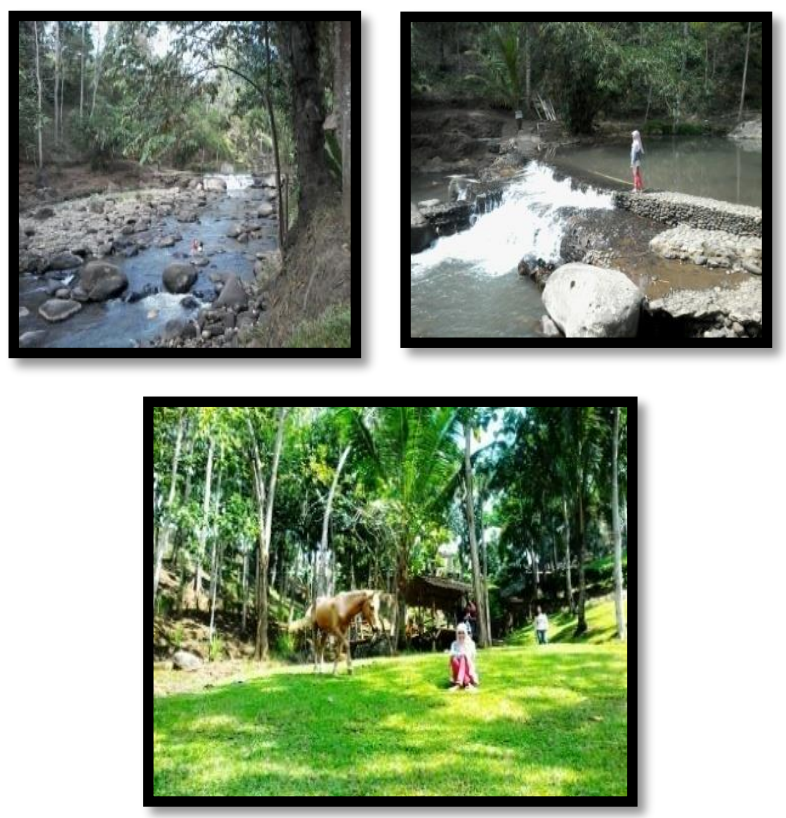

Gambar 1. Lokasi Penelitian di Kawasan Taman Wisata Alam Wira Garden

\subsection{Alat Penelitian}

Alat penelitian yang digunakan selama melakukan penelitian ini diantaranya adalah: voice recorder, camera digital, kuisioner wawancara, komputer dan perangkat lunak penunjang lainnya.

\subsection{Teknik Pengumpulan Data dan Jenis Data}

Teknik pengumpulan data dilakukan dengan cara melakukan pengamatan dan wawancara mendalam pada lokasi penelitian. Jenis data yang dikumpulkan dalam penelitian ini berupa data primer dan sekunder. Data primer yang dikumpulkan dalam penelitian ini melalui tahap wawancara dengan bantuan kuisioner dari responden pengunjung, dan key persons (Owner TWA Wira Garden, pengelola BSCH, Bank Sampah Cangkir Hijau Lampung).Wawancara mendalam hanya dilakukan pada key person saja, dengan pertimbangan untuk memperoleh data resmi penelitian. Sehingga membutuhkan waktu dan kesempatan yang lebih banyak. 99 orang responden pengunjung TWA Wira Garden dipilih dengan teknik purposive sampling (Sugiyono, 2010), yaitu sampel dipilih secara sengaja. Data sekunder diperoleh melalui informasi dari berbagai studi literatur dan instansi-instansi terkait. 


\subsection{Analisis Data}

\subsubsection{Analisis (WTP) Willingness to Pay dengan CVM (Contingent Valuation Method)}

Data yang dikumpulkan pada penelitian diperoleh dengan menggunakan metode CVM untuk mengetahui nilai (WTP) responden pengunjung. Adapun penelitian dengan menggunakan metode (WTP) ini pernah dilakukan oleh Ekayani et al. (2014), terkait pembayaran jasa lingkungan wisata alam. Penelitian ini terkait konservasi dan pemenuhan ekonomi masyarakat di TNGHS (Taman Nasional Gunung Halimun Salak).

(WTP) Willingness to Pay dihitung untuk mengetahui seberapa jauh kemampuan setiap individu atau masyarakat secara agrerat membayar atau mengeluarkan uang dalam rangka memperbaiki kondisi lingkungan agar sesuai dengan standar yang diinginkan. Tahapan CVM yang dilakukan Fauzi (2004) yaitu:

1. Membuat Hypotetical Market/Setting Up the Hypotetical Market,

2. Mendapatkan nilai penawaran (bid), dan

3. Menghitung dugaan rataan (WTP) Willingness To Pay.

Skenario/pasar hipotetis untuk WTP dibentuk agar responden lebih memahami kondisi TWA Wira Garden, sehingga tiap responden bisa memberikan nilai WTP yang lebih tepat. Seluruh responden diberi informasi mengenai skenario tersebut agar responden dapat mengetahui gambaran tentang situasi hipotetis yang dimaksud. Nilai penawaran WTP yang diajukan terhadap pengunjung responden menggunakan metode bertanya (elicitation method) dengan jenis (open-ended question). Selanjutnya diperkirakan nilai rata-rata WTP, dihitung dengan rumus (Hanley and Splash, 1993):

$$
(E W T P)=\sum_{i=1}^{n} W \mathrm{i}
$$

\section{Dimana:}

$$
\begin{array}{ll}
\text { EWTP } & \text { Dugaan Rataan (WTP) (Rp) } \\
\text { Wi } & \text { : Nilai (WTP) ke i (Rp) } \\
\mathrm{n} & \text { : Jumlah Responden (orang) } \\
\mathrm{i} & \text { : Responden ke i yang bersedia membayar } \\
& \text { tarif masuk }(\mathrm{i}=1,2,3, \ldots ., \mathrm{n})
\end{array}
$$

Kesediaan pengunjung untuk membayar lebih, sebaiknya dilengkapi dengan skenario pasar hipotetik. Hal ini dilakukan agar paket wisata berbasis pendidikan lingkungan yang diharapkan, dapat menimbulkan partisipasi pengunjung untuk lebih menjaga kelestarian lingkungan dalam upaya pengendalian sampah dan konservasi lingkungan. Skenario ini dibuat bagi pengunjung agar dapat mengetahui nilai WTP yang kiranya sanggup untuk mereka bayarkan, terkait masing-masing fasilitas dari ketiga paket wisata berbasis pendidikan lingkungan di TWA Wira Garden. Berikut deskripsi dari pasar hipotetik penerapan paket wisata pendidikan lingkungan:

\section{- Skenario 1:}

Pengunjung ditawarkan oleh pengelola terkait Paket wisata berbasis pendidikan lingkungan yang diantaranya terdiri dari tiga pilihan yaitu: (personal green, garden family, dan jungle community), masing-masing dari ketiga paket wisata memiliki aktivitas bernuansa kampanye lingkungan yang beragam, namun ketiganya sama-sama fokus melibatkan pengunjung untuk berpartisipasi secara langsung dalam menjaga lingkungan kawasan TWA Wira Garden untuk tidak membuang sampah sembarangan. Pengunjung akan mendapatkan banyak keistimewaan dari paket wisata pendidikan lingkungan. Apabila harapan pemberlakuan tarif masuk khusus direspon positif dengan kesediaan pengunjung untuk membayar lebih ke TWA Wira Garden. Adapun setelah pengunjung bersedia membeli tiket dengan harga khusus untuk paket wisata pendidikan lingkungan, maka fasilitas yang akan diperoleh adalah sebagai berikut:

$\checkmark$ Pengunjung bebas menikmati seluruh spot kawasan wisata TWA Wira Garden, baik yang di atas (View pemandangan gunung) maupun yang di bawah (Spot wisata air)

$\checkmark$ Pengunjung diajak oleh pemandu wisata untuk melakukan aktivitas wisata pendidikan lingkungan, seperti halnya apabila memilih paket pendidikan jenis garden family dan Jungle Community maka pengunjung akan mendapatkan kesempatan menanam bibit pohon di lahan yang telah disediakan, selain itu pengelola memberikan apresiasi bagi pengunjung untuk memberikan nama mereka di papan kecil dekat bibit pohon yang mereka tanam dengan istilah pengadopsi bibit pohon. Hal ini bertujuan agar menimbulkan rasa menghargai terhadap usaha untuk menjaga keberlangsungan lingkungan, selain itu untuk menarik minat pengunjung agar kembali datang dan melihat perkembangan pohon yang mereka tanam.

$\checkmark$ Pengunjung diberikan kesempatan untuk mendepositkan setiap sampah yang mereka bawa dari dalam kawasan TWA Wira Garden, dan setelah mencapai jumlah yang ditetapkan maka bisa ditukarkan dengan beragam hadiah yang menarik, seperti pulsa handphone, maupun voucher listrik. Adapun kegiatan ini dilakukan sebagai upaya memperkenalkan timbal balik positif dan rasa tanggung jawab kepada pengunjung bahwa ada apresiasi bagi setiap pengunjung yang berperan aktif ikut menjaga kebersihan TWA Wira Garden. 


\subsubsection{Analisis Penerimaan}

Perhitungan yang diperoleh pada penelitian ini untuk membandingkan jumlah penerimaan sebelum adanya paket wisata pendidikan lingkungan, dan penerimaan apabila diberlakukan paket wisata pendidikan lingkungan. Adapun yang dimaksud retribusi penerimaan yaitu (tarif masuk normal maupun tarif (WTP) dari paket wisata pendidikan lingkungan). Menurut Soekartawi (2003) yang dimaksud dengan analisis penerimaan adalah nilai $(\mathrm{P})$ harga tiket masuk dikalikan dengan jumlah pengunjung (Q), maka akan diperoleh (TR) sebagai total penerimaan dari TWA Wira Garden. Rumus untuk menghitung penerimaan TWA Wira Garden terkait penawaran paket wisata pendidikan lingkungan adalah:

$\mathrm{TR}=\mathrm{P}$ X Q

Dimana:

TR (total revenue)

$\mathrm{P}$ (price)

Q (quantity)

tahun)

: Penerimaan

: Harga (Tiket)/(WTP)

: Jumlah pengunjung (Per

Setelah diketahui diketahui perbedaan tarif tiket saat ini dan tarif tiket (WTP), maka perlu dihitung biaya operasional untuk pemberlakuan paket wisata pendidikan lingkungan. Perhitungan dilakukan dengan mengalikan sejumlah komponen biaya yang dibutuhkan untuk penerapan paket wisata pendidikan lingkungan, dengan satuan harga yang berlaku selama satu tahun (Tabel 3). Kemudian dihitung pula estimasi covering biaya operasional TWA Wira Garden setelah menerapkan paket wisata pendidikan lingkungan, yaitu dengan cara mengurangi nilai estimasi penerimaan dari tiket sesuai WTP pengunjung dengan seluruh biaya operasional yang dibebankan (Tabel 4).

Perhitungan terkait analisis penerimaan sebelumnya pernah dimodifikasi oleh Ruban et al. (2014). Dengan fokus hasil kajian penelitian menghitung total retribusi dan nilai tambah dari sistem composting dan biogas, untuk menutupi biaya operasional pengolahan sampah di Dusun Toisapu Kota Ambon.

\section{Hasil dan Pembahasan}

\subsection{Willingness to Pay (WTP) Responden Terhadap Paket Wisata Pendidikan Lingkungan}

Berdasarkan hasil wawancara, $100 \%$ responden pengunjung (99 orang) menyatakan bersedia membayar lebih untuk paket wisata pendidikan lingkungan di TWA Wira Garden. Hal ini sejalan dengan Polonsky (2011) yang menyatakan bahwa semua tipe konsumen memiliki potensi atau kemampuan untuk mendukung kegiatan ramah lingkungan, menilai komposisi kebutuhan produk lingkungan, dan menolak produk yang merusak lingkungan. Distribusi nilai WTP responden terhadap harga tiket paket wisata pendidikan lingkungan terdapat pada Tabel 1 berikut ini:

Tabel 1. Distribusi Nilai Rataan (WTP) Responden TWA Wira Garden

\begin{tabular}{|c|c|c|c|c|}
\hline \multirow[t]{2}{*}{$\begin{array}{c}\text { Paket } \\
\text { Wisata }\end{array}$} & $\begin{array}{c}\text { Nilai } \\
\text { WTP } \\
\text { (Rp/tiket/ } \\
\text { orang) }\end{array}$ & $\begin{array}{c}\text { Pengunjung } \\
\text { Frekuensi } \\
\text { (orang) }\end{array}$ & $\begin{array}{c}\text { Persentase } \\
(\mathrm{c}=\mathrm{b} / \mathrm{e} \mathrm{x} \\
100)\end{array}$ & $\begin{array}{c}\text { Rataan } \\
\text { WTP } \\
(\mathrm{Rp}) \\
(\mathrm{d}=\mathrm{a} x \\
\mathrm{b} / \mathrm{e})\end{array}$ \\
\hline & (a) & (b) & (c) & (d) \\
\hline Paket & 19.000 & 26 & 26,26 & 4.989 \\
\hline Pendidikan & 20.000 & 34 & 34,34 & 6.868 \\
\hline \multirow[t]{3}{*}{ Lingkungan } & 25.000 & 23 & 23,23 & 5.808 \\
\hline & 28.000 & 9 & 9,09 & 2.545 \\
\hline & 30.000 & 7 & 7,07 & 2.121 \\
\hline Total & & (e) 99 & 100,0 & 22.331 \\
\hline
\end{tabular}

Berdasarkan data pada Tabel 1, didapat rata-rata (WTP) sebesar (Rp. 22.331), jika pengelola TWA Wira Garden akan menetapkan tarif khusus untuk wisata pendidikan lingkungan, nilai rata-rata tersebut dapat dibulatkan menjadi sebesar (Rp 20.000/kunjungan). Pembulatan ini dilakukan untuk mempermudah pengunjung dalam proses pembayaran tiket masuk ke TWA Wira Garden. Menerapkan paket wisata pendidikan lingkungan diperlukan biaya lebih. Oleh karena itu perlu dihitung estimasi penerimaan TWA Wira Garden berdasarkan tarif tiket saat ini dan tarif tiket baru sesuai WTP pengunjung. Apabila pengelola menerapkan tarif tiket baru sesuai WTP, akan ada resiko penurunan jumlah pengunjung yang berpengaruh pada penerimaan TWA Wira Garden akibat kenaikan tarif tiket masuk.

\subsection{Estimasi Penerimaan dan Biaya Tambahan Implementasi Paket Wisata Pendidikan Lingkungan Berdasarkan Nilai WTP}

Perhitungan estimasi penerimaan dilakukan untuk membuat rencana program paket wisata pendidikan lingkungan. Dalam hal ini TWA Wira Garden membutuhkan dana tambahan untuk merealisasikan program paket wisata tersebut. Sehingga dana tersebut diharapkan mampu diperoleh dari (WTP) pengunjung. Adapun pada penelitian ini seluruh responden $(100 \%)$ bersedia untuk membayar lebih, meskipun harga yang mereka berikan cukup beragam (Tabel 2).

Apabila Dirata-rata (Tabel 1) nilai WTP pengunjung sebesar (Rp 22.331/kunjungan), dan jika diterapkan sebagai tarif baru maka perlu dilakukan pembulatkan menjadi ( $\mathrm{Rp}$ 20.000/kunjungan). Pembulatan harga tarif tiket dilakukan untuk mempermudah pengunjung dan pengelola TWA Wira Garden dalam proses pembayaran di loket. Adapun nilai WTP ini belum tentu cukup untuk merealisasikan pembuatan program paket wisata pendidikan lingkungan. Karena terdapat pengunjung yang memilih nilai WTP di bawah nilai WTP rataan. 
Oleh karena itu diperlukan perhitungan estimasi penerimaan terkait biaya yang dibutuhkan. Berdasarkan beberapa tingkatan (WTP) responden wisatawan terhadap paket wisata pendidikan lingkungan, maka diestimasi penerimaan berdasarkan beberapa skema pemberlakuan tiket wisata. Diestimasi pula jika tanpa menerapkan paket wisata pendidikan lingkungan (Tabel 2).

Tabel 2. Estimasi penerimaan TWA Wira Garden berdasarkan penerapan harga tiket WTP Pengunjung dengan dan tanpa paket wisata pendidikan lingkungan

\begin{tabular}{ccc}
\hline $\begin{array}{c}\text { Harga Tiket } \\
\text { (Rp/tiket/or } \\
\text { ang) }\end{array}$ & $\begin{array}{c}\% \\
\text { Pengunjung }\end{array}$ & $\begin{array}{c}\text { Penerimaan } \\
\text { (Rp/th) } \\
(\mathrm{c}=\mathrm{b} \times \mathrm{N} \times \mathrm{a})\end{array}$ \\
\hline (a) & (b) & (c)
\end{tabular}

$\begin{array}{lll}\text { Harga tiket saat } \quad 10.000 & 100,00 & 182.500 .000\end{array}$

ini

(tanpa paket

wisata

Pendidikan

lingkungan)

\begin{tabular}{lccr}
\hline Harga tiket & 19.000 & 100,00 & 346.750 .000 \\
Berdasarkan & 20.000 & 73,74 & 269.370 .000 \\
WTP (paket & 25.000 & 39,46 & 180.218 .750 \\
wisata & 28.000 & 16,17 & 83.293 .000 \\
pendidikan & 30.000 & 7,08 & 3.909 .150 \\
lingkungan) & & & \\
\hline N = Jumlah pengunjung tahun 2013 sebanyak 18.250 orang.
\end{tabular}

Merujuk pada Tabel 2 maka diambil jumlah nilai (WTP) dengan penerimaan tertinggi (Rp. 19.000/kunjungan). Hal ini dikarenakan jika sesuai nilai rataan (WTP) (Rp. 20.000/kunjungan), maka jumlah nilai penerimaan TWA Wira Garden hanya sebesar (Rp. 268.370.000/tahun). Sementara jika membandingkan nilai (WTP) dibawah rataan, maka diasumsikan $100 \%$ pengunjung dianggap setuju dengan tiket yang ada. Dengan nilai penerimaan sebesar ( $\operatorname{Rp}$ 346.750.000). Oleh karena itu, nilai penerimaan terbesar nantinya dapat digunakan untuk mengimplementasikan pembuatan paket wisata pendidikan lingkungan.

Setelah dilakukan analisis penerimaan, maka tahap selanjutnya adalah melakukan perhitungan besaran biaya operasional secara sederhana. Hal ini terkait untuk memberikan gambaran mengenai dana tambahan yang dibutuhkan pengelola untuk membuat paket wisata pendidikan lingkungan di TWA Wira Garden.

Biaya operasional dalam hal ini terkait rincian biaya yang dibutuhkan pihak pengelola TWA Wira Garden untuk menerapkan paket wisata pendidikan lingkungan. Rincian biaya terdiri dari item-item atau komponen yang menunjang penerapan paket wisata pendidikan. Komponen tersebut terdiri dari (biaya pembangunan loket, upah pekerja, penyediaan souvenir wisata, bibit pohon, sarana pembuatan permainan, penyediaan tong sampah, dan papan persuasif kebersihan). Adapun untuk perhitungannya dapat dilihat pada tabel 3 .
Tabel 3. Biaya Operasional Penerapan Paket Wisata Berbasis Pendidikan Lingkungan di TWA Wira Garden Kota Bandar Lampung

\begin{tabular}{|c|c|c|c|c|c|}
\hline No & Komponen & Jumlah & Satuan & Harga (Rp) & $\begin{array}{c}\text { Total (Rp)/Tahun } \\
\text { (c = c x d) }\end{array}$ \\
\hline 1 & $\begin{array}{l}\text { Biaya } \\
\text { pembangunan } \\
1 \text { buah loket } \\
\text { masuk }\end{array}$ & 12 & Bulan & 1.000 .000 & 12.000 .000 \\
\hline 2 & $\begin{array}{l}\text { Upah } 1 \text { orang } \\
\text { penjaga loket } \\
\text { masuk }\end{array}$ & 12 & Bulan & 700.000 & 8.400 .000 \\
\hline 3 & $\begin{array}{l}\text { Biaya Iklan } \\
\text { Cetak/ } \\
\text { elektronik }\end{array}$ & 1 & Paket & 2.500 .000 & 2.500 .000 \\
\hline 4 & $\begin{array}{l}\text { Tong sampah } \\
\text { dikotomi }\end{array}$ & 14 & Buah & 100.000 & 1.400 .000 \\
\hline 5 & \begin{tabular}{|l} 
Papan \\
Persuasif
\end{tabular} & 5 & Buah & 60.000 & 300.000 \\
\hline 6 & Bibit pohon & 100 & Bibit & 20.000 & 2.000 .000 \\
\hline 7 & $\begin{array}{l}\text { Souvenir } \\
\text { wisata }\end{array}$ & 18250 & Buah & 5.000 & 91.250 .000 \\
\hline 8 & $\begin{array}{l}\text { Sarana } \\
\text { Permaianan }\end{array}$ & 12 & Paket & 350.000 & 4.200 .000 \\
\hline 9 & $\begin{array}{l}\text { Biaya } 4 \text { orang } \\
\text { mentor }\end{array}$ & 12 & Bulan & 2.800 .000 & 33.600 .000 \\
\hline \multicolumn{5}{|c|}{ Total } & 155.650 .000 \\
\hline
\end{tabular}

Berdasarkan Tabel 3 diketahui bahwa untuk melakukan penerapan paket wisata pendidikan lingkungan di TWA Wira Garden diperlukan tambahan biaya operasional sebesar Rp. 155.650.000/tahun. Jika diasumsikan bahwa penerimaan pada saat tidak memberlakukan paket wisata pendidikan lingkungan, diperoleh sebesar Rp 182.500.000/tahun (Tabel 2), dan dipergunakan untuk biaya operasional TWA Wira Garden. Maka total biaya setelah menerapkan paket wisata pendidikan lingkungan terdapat pada Tabel 4.

Tabel 4. Perkiraan Jumlah Biaya Operasional TWA Wira Garden setelah Menerapkan Paket Wisata Pendidikan Lingkungan

Jenis Biaya

$$
\text { (Rp)/Tahun }
$$

\begin{tabular}{lll}
\hline 1. & Estimasi Penerimaan & 346.750 .000 \\
\hline 2. & $\begin{array}{l}\text { Biaya Tanpa Paket } \\
\text { Wisata }\end{array}$ & 182.500 .000 \\
\hline 3. & $\begin{array}{l}\text { Biaya dengan Paket } \\
\text { Wisata Pendidikan } \\
\text { Lingkungan }\end{array}$ & 155.650 .000 \\
\multicolumn{1}{c}{ Saldo } & \\
\hline
\end{tabular}

Sumber: Data Primer 2014

Tabel 4 menunjukkan bahwa paket wisata pendidikan lingkungan dapat diterapkan, karena biaya operasional dapat ditutupi oleh penerimaan dari pemberlakuan tarif tiket berdasarkan (WTP) sebesar (Rp 19.000/kunjungan). Hal ini dikarenakan jumlah penerimaan yang diperoleh dari tarif (Rp 19 000/kunjungan) sebesar Rp 346.750.000 cukup untuk memenuhi $100 \%$ biaya yang dibutuhkan untuk merealisasikan penerapan paket wisata berbasis pendidikan lingkungan di TWA Wira Garden. Bahkan dari estimasi penerimaan di atas, pihak 
pengelola masih memperoleh sisa saldo akhir, yaitu sebanyak Rp. 8.600.000. Hal ini menunjukan bahwa program paket wisata pendidikan lingkungan layak untuk diberlakukan di TWA Wira Garden. Dengan acuan pemberlakukan tarif tiket di bawah (WTP) rataan.

\section{Kesimpulan}

Berdasarkan hasil penelitian ini penetapan tarif tiket di TWA Wira Garden di bawah (WTP) rataan yaitu sebesar (Rp. 19.000/kunjungan). Kondisi ini mampu memenuhi biaya operasional untuk implementasi pemberlakuan program paket wisata pendidikan lingkungan di TWA Wira Garden.

\section{Daftar Pustaka}

[1] [BPS] Badan Pusat Statistik Provinsi Lampung, 2014. Berita Resmi Statistik Provinsi Lampung. BPS, Lampung.

[2] [Disbudpar] Dinas Kebudayaan dan Pariwisata Provinsi Lampung, 2014. Pertumbuhan Jumlah Kunjungan Wisatawan Provinsi Lampung. Disbudpar, Lampung.

[3] Ekayani M., R. Yasmin, F. Sinaga, L. Maaruf, 2014 Natural tourism at Gunung Halimun Salak National Park: A solution for ecological and economic interest. Jurnal Ilmu Pertanian Indonesia. 19 (1), pp. 29-37

[4] Fauzi A., 2004. Ekonomi Sumber Daya Alam dan Lingkungan. Gramedia Pustaka Utama, Jakarta.

[5] Hanley N., C. L. Splash, 1993. Valuing Environmental Goods: The Contingent Valuation Method. Edward Elgar Publishing Limited, London.

[6] Pearce D., R. K. Turner, I. Batemen, 1994. Environmental Economics: An Elementary Introduction Harvester Wheatsheaf. Heartfordshire, London.

[7] Ruban A., 2014. Sistem Pengolahan Sampah TPA Dusun Toisapu Kota Ambon Dengan Pendekatan Willingness To Pay. Institut Pertanian Bogor, Bogor.

[8] Sander B., 2010. The Importance of Education in Ecotourism Ventures. Substantial Research Paper. Amerika University.

[9] Soekartawi. 2003. Teori Ekonomi Produksi dengan Pokok Bahasan Analisis Fungsi. PT Raja Grafindo, Jakarta.

[10] sebagai Wahana Pelestarian Alam dan Pendidikan Lingkungan. Jurnal Manajemen Pariwisata. 5 (1), pp. 8-10.

[11] Sugiyono. 2008. Metode Penelitian Kuantitatif, Kualitatif dan $R \& D$. CV Alfabeta, Bandung.

[12] Sunu. 2010. Melindungi Lingkungan dengan Menerapkan ISO 14001. PT Gramedia, Jakarta. 